\title{
Persepsi dan Sikap Petani terhadap Penggunaan Pupuk Organik Berhara Lengkap pada Bawang Merah di Kampung Adibaboi, Distrik Manokwari Timur, Kabupaten Manokwari
}

\author{
Sari Titik Fajar Wulan Pra Romadhoni ${ }^{1}{ }^{*}$, Latarus Fangohoi ${ }^{1}$, Anastasia H.I Sabaruji ${ }^{1}$ \\ ${ }^{1}$ Program Studi Penyuluhan Pertanian Berkelanjutan, Politeknik Pembangunan Pertanian \\ Manokwari \\ *Corresponding author: sarititikfajarwulan@gmail.com
}

\begin{abstract}
Abstrak
Bawang merah (Allium ascalonicum L.) merupakan salah satu komoditas sayuran yang memiliki nilai ekonomi tinggi dalam pemenuhan konsumsi nasional, sumber pendapatan petani dan potensinya sebagai penghasil devisa negara. Kebutuhan bawang merah di Indonesia cukup besar, namun produsen bawang merah belum mampu memenuhi kebutuhan tersebut. Penelitian ini bertujuan untuk mengetahui persepsi dan sikap petani di Desa Adibaboi, Distrik Manokwari Timur, Kabupaten Manokwari. Metode penelitian yang digunakan adalah Teknik Random Sampling, menggunakan 4 perlakuan. dan 6 ulangan. Perlakuan yang diujikan pada bawang merah, variabel yang diukur meliputi tinggi tanaman, jumlah daun, bobot umbi dan bobot umbi. Pelaksanaan penyuluhan diikuti oleh 30 responden dengan materi penyuluhan tentang penggunaan pupuk organik hara lengkap dengan metode ceramah, diskusi dan demonstrasi. Jumlah skor pada persepsi sangat mudah 13 orang $(43,33 \%)$ dan kriteria mudah 12 orang (40,00\%). Skor tertinggi sikap petani terhadap penggunaan pupuk organik lengkap untuk budidaya bawang merah di Desa Adibobai adalah 5 x 30 orang $=150$ (Sangat Setuju), sedangkan skor terendah adalah 1 x 30 orang $=30$ (Sangat Tidak Setuju).
\end{abstract}

Keywords: Penyuluhan, Persepsi, Pupuk organik hara lengkap, Sikap

\begin{abstract}
Abtract
Shallots (Allium ascalonicum L.) is one of the vegetable commodities that have high economic value in terms of fulfilling national consumption, farmers' income sources and their potential as a foreign exchange earner. The need for shallots in Indonesia is quite large, but shallot producers have not been able to fulfill this need. This study aims to determine the perceptions and attitudes of farmers in Adibaboi Village, East Manokwari District, Manokwari Regency. The study method used was Random Sampling Technique, using 4 treatments. and 6 replicates. The treatments were tested on shallots, the variables measured included plant height, number of leaves, tuber weight and tuber weight. The implementation of the extension was attended by 30 respondents with extension materials on the use of complete nutrient organic fertilizers using lecture, discussion and demonstration methods. Total scores on very easy perception were 13 people (43.33\%) and easy criteria were 12 people (40.00\%). The highest score of farmers' attitudes towards the use of complete organic fertilizer for shallot cultivation in Adibobai Village was 5 x 30 people $=150$ (Strongly Agree), while the lowest score was $1 \times 30$ people $=30$ (Strongly Disagree).
\end{abstract}

Keywords: Attitudes, Complete nutrient organic fertilizer, Counseling, Perceptions 
Prosiding Seminar Nasional Pembangunan dan Pendidikan Vokasi Pertanian

Politeknik Pembangunan Pertanian Manokwari, 31 Juli 2021

e ISSN : 2774-1982

DOI : https://doi.org/10.47687/snppvp.v2i1.199

\section{PENDAHULUAN}

Bawang merah (Allium ascalonicum L.) merupakan salah satu komoditas sayuran yang memiliki nilai ekonomis tinggi ditinjau dari sisi pemenuhan konsumsi nasional, sumber penghasilan petani dan potensinya sebagai penghasil devisa negara. Bawang merah termasuk salah satu komoditas sayuran unggulan nasional yang telah lama diusahakan petani secara intensif. Produksi bawang merah sampai saat ini memang belum optimal dan masih tercermin dalam keragaman cara budidaya yang bercirikan spesifik agroekosistem tempat bawang merah diusahakan (Tahyudin et al., 2020)

Kebutuhan bawang merah di Indonesia cukup besar, namun kebutuhan tersebut belum mampu dipenuhi oleh produsen bawang merah. Kebutuhan bawang merah yang terus meningkat, tidak hanya di pasar dalam negeri, tetapi juga di luar negeri, sehingga terbuka peluang untuk ekspor ke Singapura, Malaysia dan Hongkong, namun produktivitas bawang merah di Indonesia masih rendah (Tahyudin et al., 2020).

Data BPS Indonesia tahun 2000 menunjukan bahwa produksi bawang merah secara nasional pada 3 tahun terakhir, yaitu pada tahun 2018 sebanyak 1.503.438 ton; tahun 2019 mengalami kenaikan mencapai 1.580.247 ton; namun pada tahun 2000 mengalami penurunan, hanya mencapai 772.819 ton. Bila dituinjau lebih lanjut untuk Provinsi Papua Barat, produksi bawang merah pada tahun 2018 mencapai 142 ton, dan tahun 2019 mencapai 184 ton, hal ini menunjukan peningkatan produksi sebanyak 42 ton.

Data BPS (2018), jumlah produksi bawang merah tahun 2017 sebanyak 9 ton, yang tersebar pada 5 distrik, yaitu Warmare (3 ton); Prafi (1 ton); Manokwari Utara (1 ton); Masni (3 ton); dan Sidey (1 ton). Sedangkan pada tahun 2018 (Manokwari dalam angka 2019), produksi bawang merah sebanyak 52 ton, yang tersebar pada 3 distrik yaitu Warmare (32,5 ton); Prafi (6,5 ton); dan Masni (13 ton).

Data tersebut menunjukkan bahwa produksi bawang merah di Kabupaten Manokwari mengalami kenaikan produksi sebanyak 43 ton. Hal ini merupakan potensi besar untuk terus meningkatkan jumlah produksi bawang merah melalui penggunaan pupuk dan kegiatan penyuluhan sebagai upaya membentuk persepsi dan sikap petani. Produksi bawang merah tidak terlepas dari peranan petani terutama berkaitan dengan kegiatan budidaya secara teknis dan perilaku petani secara sosial. Kegiatan teknis budidaya terkait dengan penggunaan varietas dan pupuk, sedangkan secara sosial terkait persepsi dan sikap petani terhadap komoditas bawang merah. 
Prosiding Seminar Nasional Pembangunan dan Pendidikan Vokasi Pertanian

Politeknik Pembangunan Pertanian Manokwari, 31 Juli 2021

e ISSN : 2774-1982

DOI : https://doi.org/10.47687/snppvp.v2i1.199

Petani merupakan pelaku utama dalam upaya peningkatan produksi bawang merah, oleh karena itu persepsi dan sikap petani memiliki peranan yang penting. Penggunaan pupuk berbahan organik tidak terlepas dari persepsi dan sikap petani terhadap pupuk berbahan organik tersebut. Menurut Nita et al. (2020) persepsi adalah tanggapan, penerimaan langsung dari suatu serapan, atau merupakan proses seseorang mengetahui beberapa hal melalui panca inderanya.

Kampung Adibaboi terletak di Kelurahan Pasir Putih, Distrik Manokwari Timur, Kabuputen Manokwari. Kampung tersebut memiliki potensi untuk pengembangan pertanian. Untuk memajukan sektor pertanian maka perlu upaya peningkatan kualitas usaha tani oleh masyarakat setempat. Dengan demikian diperlukan penyuluhan tentang penggunaan pupuk organik berhara lengkap pada budidaya bawang merah, dengan tujuan membentuk persepsi dan sikap petani yang positif sehingga mereka menerapkan praktik pertanian yang lebih baik melalui penggunaan pupuk organik berhara lengkap pada budidaya bawang merah.

\section{METODE PENELITIAN}

Penelitian terdiri atas dua tahap, yaitu kaji terap dan penyampaian materi penyuluhan dengan metode ceramah, diskusi, dan demonstrasi. Kaji terap bertujuan untuk mengkaji rekomendasi penggunaan pupuk berhara lengkap pada budidaya bawang merah, sehingga dapat dibuktikan dan dilihat langsung bahwa rekomendasi tersebut tepat untuk digunakan oleh masyarakat yang menjadi sasaran penyuluhan. Sedangkan penyampaian materi penyuluhan dengan metode ceramah, diskusi, dan demonstrasi bertujuan untuk menyampaikan materi hasil kaji terap, agar dapat menumbuhkan persepsi dan sikap sasaran penyuluhan yang positif terhadap penggunaan pupuk organik berhara lengkap pada budidaya bawa merah.

Kaji terap akan dilaksanakan di Kampus Politeknik Pembangunan Pertanian (Polbangtan) Manokwari, dan penyampaian materi penyuluhan dengan metode ceramah,diskusi dan demonstrasi, akan dilaksanakan di Kampung Adibaboi, Kelurahan Pasir Putih, Distrik Manokwari Timur, Kabupaten Manokwari. Keseluruhan penelitian akan dilaksanakan selama selama 3 bulan, terhitung dari bulan Maret - Mei 2021. 
Prosiding Seminar Nasional Pembangunan dan Pendidikan Vokasi Pertanian

Politeknik Pembangunan Pertanian Manokwari, 31 Juli 2021

e ISSN : 2774-1982

DOI : https://doi.org/10.47687/snppvp.v2i1.199

\section{HASIL DAN PEMBAHASAN}

Tabel 1. Persepsi Petani Terhadap Penggunaan Pupuk Organik Berhara Lengkap pada Bawang Merah di Kampung Adibaboi

\begin{tabular}{llccc}
\hline No. & Persepsi Petani & $\begin{array}{c}\text { Jumlah } \\
\text { Skor }\end{array}$ & $\begin{array}{c}\text { Kriteria Interpretasi } \\
\text { Skor }\end{array}$ & $\begin{array}{c}\text { Kriteria } \\
\text { Sikap }\end{array}$ \\
\hline 1. $\begin{array}{l}\text { Cara Penggunaan } \\
\text { Pupuk Organik }\end{array}$ & 98 & $\begin{array}{c}\text { Sangat Kuat } \\
(81,67 \%)\end{array}$ & Sangat Mudah \\
2. $\begin{array}{l}\text { Pertumbuhan dan } \\
\text { Sasil Tanaman } \\
(85,00 \%)\end{array}$ & 102 & $\begin{array}{c}\text { Cukup } \\
(55,83 \%)\end{array}$ & Sangat Bagus \\
3. $\begin{array}{l}\text { Biaya Penggunaan } \\
\text { Pupuk }\end{array}$ & 67 & & Murah \\
\hline
\end{tabular}

Berdasarkan tabel diatas dapat disimpulkan bahwa petani di Kampung Adibaboi mempersepsikan pupuk organik berhara lengkap sangat mudah dilakukan, sangat bagus bagi pertumbuhan dan hasil tanaman; dan biaya penggunaan murah. Persepsi petani di Kampung Adibaboi seperti yang digambarkan diatas sejalan dengan pendapat Hamka (2002) dan Fangohoi (2018) yang menyebutkan dua indikator persepsi yaitu menyerap dan mengerti. Persepsi petani dalam kajian ini bersumber dari keikutsertaan petani dalam kegiatan penyuluhan, dimana petani menyerap dan mengerti materi penyuluhan tentang penggunaan pupuk organik berhara lengkap pada bawang merah yang disampaikan. Pendapat tersebut juga di dukung oleh Saputra et al. (2018) yang menyebutkan proses terjadinya persepsi diawali dari suatu objek yang menimbulkan stimulus, kemudian stimulus tersebut mengenai alat indra atau reseptor. Persepsi petani di Kampung Adibaboi terhadap pupuk organik berhara lengkap karena ada objek yang diamati saat menerima materi penyuluhan. Objek tersebut dapat berupa materi yang disampaikan dan media yang digunakan saat penyuluhan. Objek tersebut menjadi stimulus dan kemudian mengenai alat indra (mata dan telinga) petani yang menghasilkan persepsi petani.

\section{Sikap petani terhadap penggunaan pupuk organik berhara lengkap pada bawang merah}

Sikap petani adalah respon petani berupa pernyataan setuju atau tidak setuju terhadap objek tertentu (Fangohoi, 2016; Anggini, et al. 2019; Malik, et al. 2020). Data sikap yang diperoleh dari penelitian ini dianalisis dengan menggunakan statistik deskriptif (rata-rata dan persentase) untuk mendeskripsikan sikap petani pada tujuan kedua dalam penelitian ini. Skala Likert digunakan untuk menganalisis sikap petani terhadap penggunaan pupuk organik berhara lengkap pada bawang merah setelah penyuluhan di Kampung Adibaboi mencakup enam pernyataan sikap petani yaitu: 1) 
Prosiding Seminar Nasional Pembangunan dan Pendidikan Vokasi Pertanian

Politeknik Pembangunan Pertanian Manokwari, 31 Juli 2021

e ISSN : 2774-1982

DOI : https://doi.org/10.47687/snppvp.v2i1.199

penggunaan pupuk organik berhara lengkap dapat meningkatkan pertumbuhan dan hasil bawang merah; 2) budidaya bawang merah dengan menggunakan pupuk organik berhara lengkap akan memperoleh hasil yang menguntungkan; 3) senang menggunakan pupuk organik berhara lengkap karena mudah dalam penggunaannya; 4) tidak akan menggunakan pupuk organik berhara lengkap pada budidaya bawang merah karena mahal biaya produksinya; 5) akan menyarankan petani lainnya untuk menggunakan pupuk organik berhara lengkap; dan 6) merasa berat untuk membeli pupuk organik berhara lengkap karena harganya cukup mahal.

Tabel 2. Sikap Petani Terhadap Penggunaan Pupuk Organik Berhara Lengkap Pada Bawang Merah di Kampung Adibaboi

\begin{tabular}{ccccc}
\hline No. & $\begin{array}{r}\text { Pernyataan } \\
\text { Sikap }\end{array}$ & $\begin{array}{c}\text { Jumlah } \\
\text { Skor }\end{array}$ & $\begin{array}{c}\text { Kriteria Interpretasi } \\
\text { Skor }\end{array}$ & $\begin{array}{c}\text { Kriteria } \\
\text { Sikap }\end{array}$ \\
\hline 1. & Pernyataan 1 & 128 & Sangat Kuat $(85,33 \%)$ & Sangat Setuju \\
2. & Pernyataan 2 & 122 & Sangat Kuat $(81,33 \%)$ & Sangat Setuju \\
3. & Pernyataan 3 & 112 & Kuat $(74,67 \%)$ & Setuju \\
4. & Pernyataan 4 & 75 & Cukup $(50,00 \%)$ & Ragu-ragu \\
5. & Pernyataan 5 & 92 & Kuat $(61,33 \%)$ & Setuju \\
6. & Pernyataan 6 & 74 & Cukup $(49,33 \%)$ & Ragu-ragu \\
\hline
\end{tabular}

Berdasarkan tabel diatas dapat disimpulkan bahwa sikap petani bervariatif terhadap pupuk oranik berhara lengkap yang diperkenalkan melalui kegiatan penyuluhan di Kampung Adibaboi diperkenalkan melalui kegiatan penyuluhan di Kampung Adibobai. Banyaknya petani yang menjawab sangat setuju menunjukkan kegiatan penyuluhan efektif selaras dengan laporan Mardiyanto et al. (2020). Petani memiliki sikap sangat setuju pada pernyataan 1 (penggunaan pupuk organik berhara lengkap dapat meningkatkan pertumbuhan dan hasil bawang merah), dan pernyataan 2 (budidaya bawang merah dengan menggunakan pupuk organik berhara lengkap akan memperoleh hasil yang menguntungkan).

Petani memiliki sikap Setuju pada pernyataan 3 (senang menggunakan pupuk organik berhara lengkap karena mudah dalam penggunaannya), dan pernyataan 5 (akan menyarankan petani lainnya untuk menggunakan pupuk organik berhara lengkap). Petani memiliki sikap ragu-ragu terhadap pernyataan nomor 4 (tidak akan menggunakan pupuk organik berhara lengkap pada budidaya bawang merah karena mahal biaya produksinya), dan pernyataan 6 (merasa berat untuk membeli pupuk organik berhara lengkap karena harganya cukup mahal). 
Prosiding Seminar Nasional Pembangunan dan Pendidikan Vokasi Pertanian

Politeknik Pembangunan Pertanian Manokwari, 31 Juli 2021

e ISSN : 2774-1982

DOI : https://doi.org/10.47687/snppvp.v2i1.199

Hubungan antara persepsi dan sikap petani terhadap penggunaan pupuk organik berhara lengkap pada bawang merah

Analisis hubungan antara persepsi dan sikap petani dalam penelitian ini menggunakan analisis statistik inferensial, yaitu Uji Product Moment pada taraf 5\% (jika terpenuhinya syarat uji statistik parametis), atau Uji Spearman Rank Correlation pada taraf 5\% (jika tidak terpenuhinya syarat uji statistik parametis). Analisis statistik inferensial tersebut untuk menganalisis hubungan antara persepsi dan sikap petani pada tujuan ketiga penelitian ini.

Tabel 3. Analisis Normalltas Data Menggunakan Uji Product Moment

\begin{tabular}{|c|c|c|c|c|c|c|}
\hline & \multicolumn{6}{|c|}{ Tests of Normality } \\
\hline & \multicolumn{3}{|c|}{ Kolmogorov-Smirnov ${ }^{a}$} & \multicolumn{3}{|c|}{ Shapiro-Wilk } \\
\hline & Statistic & df & Sig. & Statistic & df & Sig. \\
\hline Persepsi Petani & .216 & 30 & .001 & .867 & 30 & .001 \\
\hline Sikap Petani & .248 & 30 & .000 & .772 & 30 & .000 \\
\hline
\end{tabular}

Hasil output SPSS diatas menunjukkan bahwa persepsi petani memiliki nilai sig (signifikansi) sebesar 0.001 dan sikap petani memiliki nilai sig (signifikansi) sebesar 0.0,0. Kedua nilai tersebut lebih kecil dari tingkat alpha yaitu $0,001<0,05$ dan $0,000<$ 0,05 , artinya kedua data tersebut tidak berdistribusi normal. Dengan demikian syarat Uji Product Moment pada taraf 5\% belum terpenuhi, sehingga tidak dapat digunakan. Uji Product Moment akan gunakan jika syarat signifikansi > 0,05, maka data dapat dikatakan berdistribusi normal. Selanjutnya akan digunakan Uji Spearman Rank Correlation pada taraf 5\%, karena tidak mempertimbangkan syarat data berdistribusi normal.

Tabel 4. Analisis Korelasi Persepsi dan Sikap Petani Menggunakan Uji Korelasi Spearman

\begin{tabular}{lllrr}
\hline & & Persepsi Petani & \multicolumn{2}{c}{ Sikap Petani } \\
\hline Spear & Persepsi & Correlation & 1.000 & $.740^{* *}$ \\
man's & Petani & Coefficient & & \\
rho & & Sig. (2-tailed) & 30 & .000 \\
& & $\mathrm{~N}$ & $.740^{* *}$ & 1.000 \\
\cline { 2 - 5 } & Sikap Petani & Correlation & & \\
& & Coefficient & .000 &. \\
& & Sig. (2-tailed) & 30 & 30 \\
\hline **. Correlation is significant at the 0.01 level (2-tailed). & &
\end{tabular}


Prosiding Seminar Nasional Pembangunan dan Pendidikan Vokasi Pertanian

Politeknik Pembangunan Pertanian Manokwari, 31 Juli 2021

e ISSN : 2774-1982

DOI : https://doi.org/10.47687/snppvp.v2i1.199

Hasil output SPSS diatas menunjukkan $\mathrm{N}$ atau jumlah responden sebanyak 30 orang petani. Nilai sig (2-tailed) sebesar 0,000. NIlai tersebut lebh kecil dari nilai alpha (sig < 0.05), maka dapat diambil keputusan ada hubungan yang siginfikan antara persepsi dan sikap petani. Nilai Correlation Coefficient sebesar 0,740 menunjukkan hubungan yang tinggi antara persepsi dan sikap petani yang ditunjukkan dari angka 0,740 mendekati angka 1,000. Correlation Coefficient bernilai positif menunjukkan bahwa persepsi dan sikap petani memiliki hubungan searah, artinya jika persepsi meningkat maka sikap ikut meningkat sesuai dengan pernyataan Helmi, et al. (2019). Jika petani memiliki persepsi yang baik terhadap penggunaan pupuk organik berhara lengkap pada bawang merah, maka sikap petani pun akan memberikan penilaian yang baik pula terhadap penggunaan pupuk organik berhara lengkap pada bawang merah.

\section{KESIMPULAN DAN SARAN}

Penelitian ini menyimpulkan sebagai berikut:

1. Persepsi petani terhadap penggunaan pupuk organik berhara lengkap pada bawang merah setelah penyuluhan di Kampung Adibaboi menunjukkan persepsi sangat mudah menggunakan pupuk organik, sangat bagus pertumbuhan dan hasil tanaman, dan murah biaya penggunaan pupuk.

2. Sikap petani terhadap penggunaan pupuk organik berhara lengkap pada bawang merah setelah penyuluhan di Kampung Adibaboi menunjukkan sikap yang bervariatif yaitu sangat setuju (pernyataan 1 dan 2); setuju (pernyataan 3 dan 5); dan ragu-ragu (pernyataan 4 dan 6).

3. Hubungan antara persepsi dan sikap petani terhadap penggunaan pupuk organik berhara lengkap pada bawang merah di Kampung Adibaboi menunjukkan ada hubungan yang siginfikan antara persepsi dan sikap petani, dimana hubungan tersebut sangat tinggi dan searah.

Berdasarkan kesimpulan di atas, maka dapat disarankan sebagai berikut:

1. Perlu dilakukan kegiatan penyuluhan lanjutan untuk meningkatkan pengetahuan petani agar dapat membentuk persepsi petani yang lebih kuat dan bukan persepsi yang bersifat sementara, sehingga dapat membentuk sikap dan perilaku (tindakan) yang mempercepat proses adopsi dan difusi inovasi pupuk organik berhara lengkap di tingkat petani.

2. Perlu dilakukan kegiatan pemberdayaan petani berupa kegiatan pendamping petani dan mitra desa antara stakeholder lingkup pertanian, misalnya dinas pertanian, LSM, 
Prosiding Seminar Nasional Pembangunan dan Pendidikan Vokasi Pertanian

Politeknik Pembangunan Pertanian Manokwari, 31 Juli 2021

e ISSN : 2774-1982

DOI : https://doi.org/10.47687/snppvp.v2i1.199

dan lembaga pendidikan, dengan pertimbangan bahwa Kampung Adibaboi merupakan kampung yang baru dibentuk (persiapan kampung definitif) yang terletak di pinggiran kota Manokwari.

3. Perlu dilakukan kegiatan penelitian lanjutan penggunaan pupuk organik berhara lengkap pada beberapa jenis tanaman yang dominan di budidayakan oleh petani di Kampung Adibaboi agar dapat mendorong petani menggunakan pupuk organik dan menghindari petani dari penggunaan pupuk berbahan kimia.

\section{DAFTAR PUSTAKA}

Anggini, D., Hartono, R., \& Anwarudin, O. (2019). Perilaku petani dalam pemanfaatan limbah sayuran sebagai pupuk bokashi pada tanaman sawi putih, Jurnal Triton, 10(1), 99-115.

BPS. (2018). Manokwari dalam Angka Tahun 2018.

BPS. (2000). Data Produksi Tanaman Sayuran 2000.

Fangohoi, L. (2016). Model Penyuluhan Pertanian Dalam Agribisnis Kakao "Cyber Extension" (Studi Kasus Di Desa Yoom Kecamatan Manokwari Utara Kabupaten Manokwari Propinsi Papua Barat), Jurnal Triton, 7(2), 35-48.

Fangohoi, L., Sugiyanto, S., Sukesi, K., \& Cahyono, E.D. (2018). Establish the perception of agricultural extension workers through cyber extension as the media information, Journal of Socioeconomics and Development, 1(1), 32-37.

Hamka. (2002). Psikologi Pendidikan. Jakarta: Rineko Cipta.

Helmi, Z., Haryanto, Y., Anwarudin, O., \& Trisnasari, W. (2019) Paradigma Penyuluhan di Era Teknologi Informasi. Makassar: CV Tohar Media.

Malik, R.J., Hariadi, S.S., Witjaksono, R., \& Priyotamtama, P.W. (2020). Konsistensi Sikap Petani terhadap Kemampuan Mengakses Informasi Teknologi Pertanian di Kabupaten Pacitan. Jurnal Triton. 11(2), 22-31.

Mardiyanto, T.C., Samijan, S., \& Nurlaily, R. (2020). Efektivitas Metode Penyuluhan dalam Desiminasi Budidaya Bawang Putih Ramah Lingkungan di Kabupaten Karanganyar. Jurnal Triton, 11(1), 45-57.

Nita, D.R., Anwarudin, O., \& Nazaruddin, N. (2020) Farmer Regeneration Through Development of Youth Interest in SFHA Activities in Sukaraja District, Bogor Regency, Jurnal Penyuluhan Pertanian, 15(1), 8-12.

Saputra, C., Anwarudin, O., \& Sulistyowati, D. (2018) Persepsi dan adopsi pengendalian hama terpadu lalat buah pada tanaman mangga di Kecamatan Greged Kabupaten Cirebon Provinsi Jawa Barat, Jurnal Penyuluhan Pertanian, 13(2), 46-60.

Tahyudin, T., Anwarudin, O., \& Hartono, R. (2020) Perilaku petani dalam mereduksi penggunaan pestisida kimia pada budidaya bawang merah. Jurnal Kommunity Online, 9(1), 211-30. 